\title{
Children and young people's behaviour in accidental dwelling fires: a systematic review of the qualitative literature
}

\begin{abstract}
Children and young people are considered one of the most vulnerable population groups when exposed to accidental dwelling fires. Understanding how children behave in these circumstances and the reasons for their decision making are important to support rescue and fire safety education. We undertook a systematic review of the qualitative literature to identify studies where children and young people were asked to recount their experiences of being in an accidental dwelling fire in order to inform UK Fire and Rescue Service training and fire safety education programmes. We found no studies designed specifically to explore children's behaviours in dwelling fires, and only four studies (including 39 children's stories) where their behaviours had been recorded coincidentally to the main study aim. The evidence arising from these stories was frequently incomplete, often out of date (1520 years old), and 38/39 (97\%) of stories were from the United States. This review indicates there is inadequate evidence of the current lived experience of children in accidental dwelling fires to support fire and rescue services in either their fire and rescue training or community fire safety education activities, particularly for non-US countries.
\end{abstract}

(165 words)

Keywords 
Children and young people, Human behaviour, Fire evacuation, Accidental fires, Dwelling fires.

\subsection{Introduction}

1.1 There were 39,600 dwelling fires in Great Britain in 2013-14 (Department for Communities and Local Government 2015), and of these $89 \%$ were accidental. Dwelling fires remain the main cause of fire-related deaths in Great Britain. The main cause of accidental dwelling fires is the misuse of equipment or appliances and the main source of ignition is cooking appliances, accounting for half of all accidental dwelling fires (Department for Communities and Local Government 2015). The trend in falling numbers of dwelling fires over the last decade is most likely to be associated with the increasing proportion of homes with working smoke alarms. Despite smoke alarm ownership being estimated to be as high as $88 \%$ in the UK in 2011 (Department for Communities and Local Government 2014a), 57\% of fire fatalities and $41 \%$ of non-fatal casualties occurred in homes where a smoke alarm was absent or present but not working. The UK Fire and Rescue Service (FRS) identifies children and the older people as the two most vulnerable groups in dwelling fires. Of the 258 people who died in dwelling fires, the age group most affected are those over 80 years of age (Department for Communities and Local Government 2015). Of these, only 29 children and young people (up to the age of $25 \mathrm{y}$ ) died in fires in Great Britain in 2013-14, but a much larger (and unrecorded) number of children and young people will have experienced a fire in their home. The risk of being injured in a fire is socially patterned and associated with multiple nonindependent factors (Holborn 2003, DCLG 2014) including household members 
using tobacco products, alcohol and drugs, household members being unwell or having a disability and failing to have a working smoke alarm. A study of FRS data between 1994 and 2004 (Mulvaney 2009) showed that Fire and Rescue Services based in the most deprived areas of the UK had local fire injury rates between 1.4 and 3.7 times higher than Fire and Rescue Services in areas of the least deprivation, with a dose-response relationship, i.e. the greater the degree of deprivation, the greater the number of fire related injuries occurring in that area. These deprivation gradients had not changed over the 10 year period of study (Mulvaney 2009).

\subsection{The Kent Fire and Rescue Service have recently been working with the} University of Greenwich to investigate the behaviour of people over the age of 16 years who experience an accidental dwelling fires. They have been exploring the extent to which adults follow current FRS guidance to "Get out, stay out and call 999". A qualitative study of 179 adults who had experienced a fire at home revealed that people often attempt to tackle fires themselves, will carry out actions that are specifically discouraged by the FRS (such as re-entering the room of origin of the fire) and will re-enter property having left the building to retrieve other occupants, possessions or pets (Wales and Thompson 2012). This study has led to the creation of an on-going database of information on adult behaviour in accidental dwelling fires being collected from multiple FRS from across England, and facilitating the identification of themes with the potential to influence FRS stakeholder practice, and informing how public safety messages may need to be revised (Wales 2015).

1.3 How an individual behaves in a dwelling fire is dependent on features which include their ability to make decisions and how that may be influenced by being in a 
stressful environment such as a dwelling fire, their ability to observe and interpret danger signals with subsequent estimation of risk, and their mobility to respond to that risk appropriately (Kobes 2010). The challenge of managing potentially conflicting impulses driven by cognition and emotion in a fire evacuation situation is well recognised (Kinateder 2015, Clark 2015a). Behaviours identified in adults should not be generalised to children and young people. The behavioural features may differ from those in adults, and are likely to vary during their childhoods, dependent on the age and stage of the child's development. Reports of children's involvement in domestic fires tend to be in the form of epidemiological studies of fire injury and fatality incidence or case series (Shai 2003, Holborn 2003, Mulvaney 2009, Hussain 2014). Such reports do not include the voice of the child. The most appropriate study design to explore individuals' perceptions and behaviours is through qualitative methods. These techniques allow an exploration of choice and decision making, leading to a greater depth of understanding of the factors that have influenced subsequent actions (Corbin 2015). This in turn facilitates the inductive generation of hypotheses which can be used to inform the development of interventions and later testing through quantitative studies (Bowling, 2014). It is increasingly recognised that research designed to improve outcomes for children and young people is strengthened by the inclusion of children and young people in the research. This principle is enshrined in the United Nations Convention on the Rights of the Child (United Nations, 1989) and in the UK Children Acts of 1989 and 2004 (Children Act 1989, Children Act 2004). Public participation in research is recognised as contributing to the improved validity and potential impact of study outcomes and the ability to generalise study findings beyond the academic setting (INVOLVE, 2012). Hearing the voice of the child is now widely recognised as good 
practice, is promoted by advocates for children such as the UK Chief Medical Officer (Chief Medical Officer, 2012) and by children themselves (McDonagh, 2012) and demonstrates a marked shift from historical approaches where research was done to children or on children (Bird, 2013).

1.4 Information on the circumstances of UK fires that are fatal for children and young people are collected through Fire Investigation Reports, Coroners Reports and the work of the Child Death Overview Panels (HM Government 2015). However, relatively little is known about how the behaviours of children who survive an accidental dwelling fire differ from those who do not. Here again, the literature is largely focused on the behaviour and lifestyles of adults, but is mostly more than 15 years old (Runyon 1992, Marshall 1998, Warda 1999) or from non-UK settings (Diekman 2012, Xiong 2015). Evidence emerging from research on adult behaviour in fires suggests that understanding pre-evacuation behaviour is as important as behaviour during evacuation (Zhao 2009). As the number of children who experience a fire at home but are not killed or seriously injured is much greater than the number who are harmed, it seems appropriate to understand how the behaviour of those who survive unharmed differs from the behaviour of those who are harmed. This knowledge has the potential to support two important areas; fire officer training and fire safety education. UK Fire officers entering a burning building to search for children are trained to look under beds and in wardrobes on the assumption that children will hide from fire (Department for Communities and Local Government 2014b). Conversations with several UK fire personnel indicate that this practice appears to be built upon the location of fatal child fire victims. It is not clear whether this behaviour is dependent on the stage of the fire or the age of the child. In 
addition, Fire and Rescue Service pro-actively engage with pre-schools, primary and secondary schools to teach fire safety to children. It is important that they have accurate information on the behaviour of children in dwelling fires to know how best to advise children how to behave if they find themselves in this situation. Currently most research on human behaviour in fires in the UK setting has been focussed on the behaviour of adults (Thompson 2014, Wales 2015, Clark 2015b). The aim of this study was therefore to identify the literature reporting the behaviour of children and young people in accidental dwelling fires, to collate and summarise that knowledge.

\subsection{Methods}

2.1. To avoid the risk found with some literature reviews of only reporting evidence supporting preconceived beliefs, we used a systematic literature review methodology that involved pre-specification of the criteria for including a study in the review, a search strategy that enabled reproducible identification of literature meeting those criteria (published and unpublished), and critical appraisal of included studies prior to inclusion in a synthesis of findings (Pope 2007, Gough 2012). Due to our concern that parental or adult interpretation of child behaviour may be incorrect, the inclusion criteria specified the need for evidence collected from children and young people themselves, rather than being reported by a third party.

\subsection{Inclusion criteria}

We searched for studies meeting the following inclusion criteria:

a) Participants: the study population was children and young people under the age of 18 years, i.e. a 'child' as defined by the United Nations (UN General 
Assembly, 1989) and living in a high income country (as defined by the World Bank);

b) Exposures: experience of being in an accidental or unintentional fire at home, where home was defined as their place of usual residence;

c) Outcomes: actions taken during the fire experience and where possible, the rationale for the decision to take that action. Actions to be reported by the child.

d) Study design: qualitative studies where children were asked / interviewed about their behaviours, motivations, actions and outcomes during the fire.

We applied the following exclusion criteria to limit the search

a) Setting: we excluded studies from low and middle income countries in order to identify evidence more likely to be relevant to the UK setting and the UK Fire and Rescue Service.

b) Language: we excluded studies not reported in English due to the absence of funding available for translation.

c) Intentionally set fires: we excluded studies that were solely about the experiences and actions of fire setters, since we believed that the behaviours and decision making of children who had intentionally set fires would be likely to be different to those who unexpectedly found themselves in a fire at home. No date restrictions were applied.

\subsection{Search strategy}

To identify relevant studies, electronic databases were searched using a strategy developed in Medline using free text and thesaurus terms for the concepts of 'children' and 'dwelling fires'. To improve sensitivity, the search strategy was 
intentionally broad; (1) (child* or young ${ }^{*}$ or adolesc ${ }^{*}$ or toddler* or pre-school $^{*}$ or youth $^{*}$ or teen ${ }^{*}$ or pediatric ${ }^{*}$ or paediatric* or infant $^{*}$ ) (2) Exp. Child/ (3) (house* or dwelling $^{*}$ or flat ${ }^{*}$ or high-rise ${ }^{*}$ or home ${ }^{*}$ or apartment ${ }^{*}$ or residential ${ }^{*}$ or domestic ) adj fire*) (4) (1 or 2$)$ and 3.

We applied the search history to 10 electronic databases; MEDLINE (1966 to Feb 2015), EMBASE (1947 to Feb 2015), CINAHL (Cumulative Index to Nursing and Allied Health Literature (1937 to Feb 2015) PsycINFO (1806 to Feb 2015), SocINDEX Index (1895 to Feb 2015), ERIC (Educational Resources Information Centre) (1966 to Feb 2015), Child Development and Adolescent Studies (1927 to Feb 2015), ASSIA (Applied Social Sciences Index and Abstracts) (1987 to Feb 2015), BNI (British Nursing Index) (1985 to Feb 2015) and Social Services Abstracts (1979 to Feb 2015).

In addition to the electronic databases we also searched a range of grey literature sources. We searched a number of conference programmes and proceedings (Interflam 2004, 2007, 2010, 2013; the UK Fire Service College Research and Development Event annual conference (2010 to 2014); Fire '92 conference proceedings; and the proceedings of the 2013 International Symposium of Human Behaviour in Fire) to identify authors and abstracts meeting our inclusion criteria. We searched the Library Catalogue of the UK Fire Service College, using the terms 'child' and 'adolescent'. This search included books, specialist journals (Fire, Fire Safety, Technology and Management, Fire Safety Journal, Fire International, Fire Prevention, Firehouse, Emergency) and projects and theses produced by fire officers completing further training qualifications. We contacted academic departments specialising in human behaviour in fires and local fire service colleagues. Finally we 
attempted to contact all authors of included studies to seek additional information and identify further studies.

\subsection{Study selection}

In order to determine which studies should be included in the review we applied a structured and objective screening process to all of the citations arising from application of the search strategy. Studies were only included in the review if they met all of the pre-specified inclusion criteria. Failure to meet any one of the inclusion criteria led to exclusion of that study. The first stage of study selection involved reviewing the title and abstract of each citation. Where it was clear from either the title, abstract or key words that at least one of the inclusion criteria was not met, this study was excluded. The full text of any citations remaining after the initial screening were then obtained, so that these studies could be read in full to determine if they met all of the inclusion criteria. Authors were contacted where possible and necessary to establish eligibility. In order to reduce the risk that eligible studies could be missed, the screening was undertaken by two researchers and then independently checked by a third researcher.

\subsection{Management of studies included in the review}

To facilitate data synthesis, a data extraction spreadsheet was developed by the research team. This was based upon a domestic fire 'time-line' approach used in a recent studies of adult behaviour in fires (Thompson 2014, Kinateder 2015). For each paper (and additional data where provided), data were extracted on study design, methodology, participant characteristics (e.g. age and gender), 
circumstances of the fire, and details of self-reported behaviours and actions during the fire. Where data were reported, we recorded information on: what were they doing before they knew there was a fire; how did they know there was a fire; what was the first thing they did and the rationale for doing so, subsequent actions and rationales, how they escaped from the fire, how the fire was put out, and what happened after the fire. Data were also extracted on author reported strengths and limitations of their study and the author's conclusions. Included studies were critically reviewed to explore the quality of the study and to indicate the potential for bias in the reported study findings. Data for the studies were analysed using a narrative synthesis seeking similarities and differences between the included studies and consistency in findings across settings and participants (Petticrew 2006).

\subsection{Results}

3.1 The systematic search of ten electronic databases and grey literature sources identified 1282 potential citations, of which 1021 were unduplicated (Figure 1). A total of 972 records were excluded on screening of titles, abstracts and keywords leaving 49 records for full text review. 
Figure 1: Flowchart of included studies
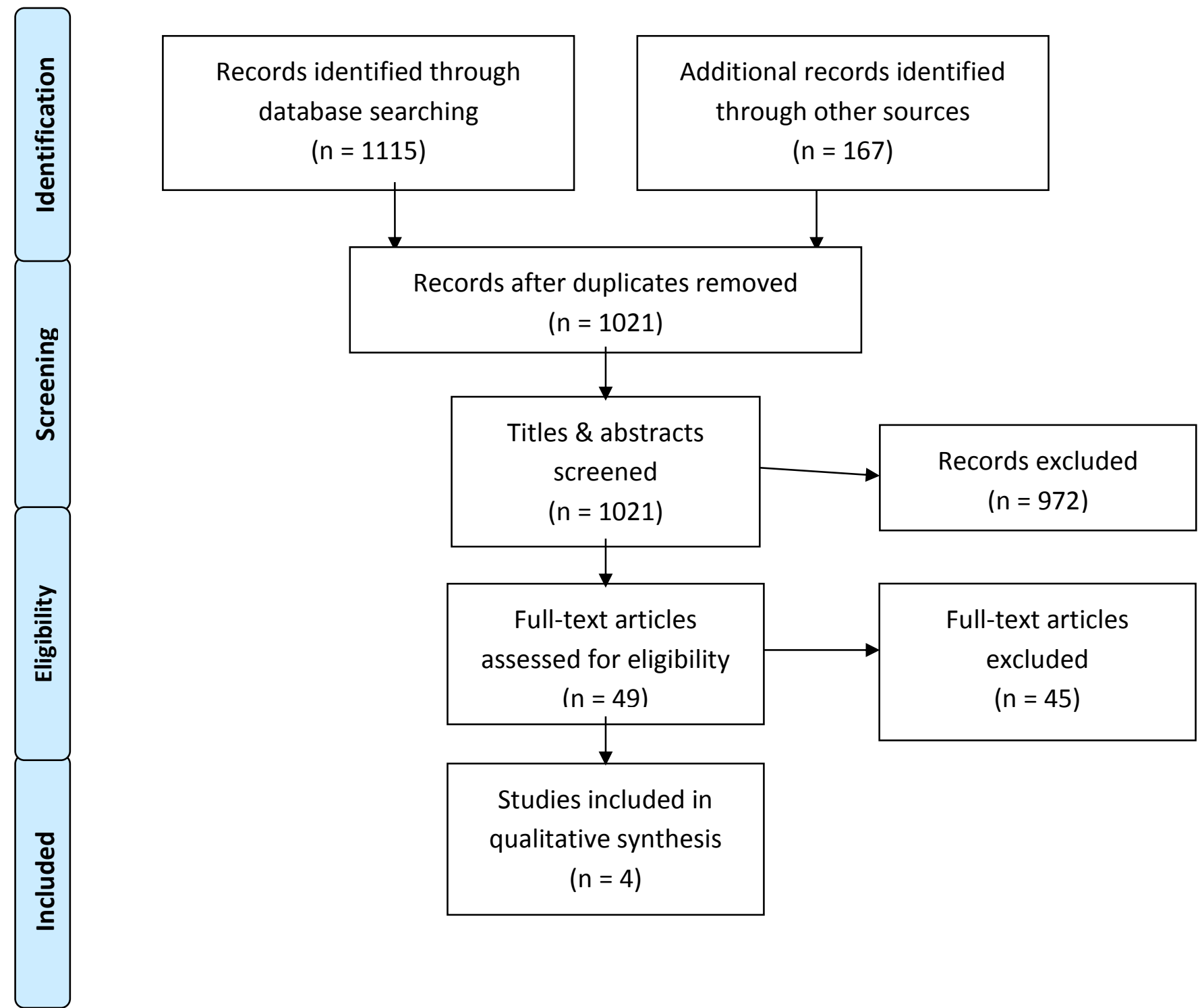

3.2 The full text review of 49 papers indicated that 7 were duplicate references or additional papers reporting the same study identified from another source. When these were removed the full texts of the remaining 42 independent studies were assessed to determine if each of the four inclusion criteria were met. Four studies met all four inclusion criteria (Dowling 1997, Greenberg 1984, Jones 2012, and Park 
1995). The remaining 38 studies were excluded due to failing to meet the following criteria; None of the 38 studies reported the outcome of children's behaviour during a domestic fire told in the child's voice, $24 / 38$ studies were not qualitative in design, $22 / 38$ included only adult participants or it was not possible to determine children's responses from those of adults, and $7 / 38$ were excluded because they were not reports of domestic fires, but of fires in public buildings or reports of domestic fires when the child / children were not at home.

3.3 Of the four studies meeting the four inclusion criteria, none were specifically designed with the aim of exploring how children behaved during a domestic dwelling fire. Instead, these four studies reported children's behaviour during domestic fires co-incidentally to the main aim of the study. Two of these studies (Greenberg 1994, Jones, 2012) were designed to explore the psychological consequences of being in a fire at home and during the interview children were asked about the fire event which gave some information on how the child acted during the fire. The remaining two studies (Dowling 1997, Park 1995) were designed to evaluate the effectiveness of fire safety training programmes by asking children who had attended training and had subsequently been in a fire at home, to describe their actions. Each of these four studies is described below before a narrative synthesis of findings across the studies is provided. Critical appraisal of the quality of the four studies indicated that none of them reported their methods at a level of detail that enabled us to be confident that there was no risk of bias in their results.

3.4 Greenberg (1994) interviewed 12 children, aged between 6 and 17 years who had experienced fires at home in a mid-Atlantic city in the USA. The study was 
designed to explore their physical and psychological behaviours after the fire and to consider the implications of these findings for social work services. The interview guide included questions such as "Tell me about the fire. What was it like for you?" and "Did you have to escape?" None of the individual children's stories were included in the published manuscript, only the themes emerging from analysis of the interview transcripts, and therefore the content of this study was not suitable for inclusion in a synthesis of included studies. We were unable to contact Greenberg or to identify any subsequent papers by the same author.

3.5 Jones et al (2012) reported the analysis of interviews, collected in 1999, with 44 children and adolescents aged 6-18 years who had participated in a National Institute of Mental Health funded study of children's stress responses to accidental fires and the risk of developing post-traumatic stress disorder (Jones 2002). The interview used a 16-item fire questionnaire which included 2 questions relevant to this study; "Tell me about the recent fire you experienced" and "Take me through that experience step by step". We obtained copies of original interview transcripts from the author for inclusion in this analysis. Of the transcripts provided over half were excluded as they were either incomplete or the child was not resident in the building at the time of the fire, leaving 19 children's stories for inclusion in our synthesis. The transcripts held brief accounts of the actions of 19 children in the fire, but the request to 'take me through that step by step' did not appear in every transcript and detail regarding the actions of the child was rarely pursued by the interviewer. This is perhaps not surprising since the focus of the study was the psychological consequences of the experience rather than the experience per se. The available 
'stories' therefore were frequently limited to a few sentences containing little detail regarding actions and less regarding the rationale for the decisions made.

3.6 Dowling (2002) reported a pilot study to evaluate the UK Cheshire Fire and Rescue Service fire safety education programme for children aged 9-10 years. Dowling presented a single case study in which a child provided a written account for his teacher of his behaviour in a fire at his home. The written account was subsequently used as a guide for an interview with a fire officer from the local fire and rescue service, to explore the reasons for the actions written in the account of the fire. Dowling concluded that the two-stage process provided a valid method for identifying actions that could, or could not, be attributed to the training received at school prior to the fire event. We confirmed with the author that there had not been a subsequent study to implement these methods, and that no further stories from children experiencing fires after the Cheshire Fire and Rescue Service fire safety education programme had been obtained.

3.7 The study by Park (1995) was a report of a Command Course International Project by a UK fire officer who reviewed fire safety programmes in the US and explored their potential applicability to the UK. Park collated and presented the stories of children reported to have used their education knowledge gained through a US programme called 'Learn not to burn' that had been identified by the National Fire Protection Association. A total of 19 stories of children's behaviour in fires at the domestic residence where they were staying, and occurring after exposure to the 'Learn not to burn' programme were included in this analysis. Although a significant proportion of these stories were second-hand (i.e. a record of what the children were 
said to have reported, but not collected directly from the children by the author), a decision was taken to include them in the synthesis due to the fact that specific actions were described and attributed to the programme, and the inclusion of quotes from some children.

3.8 Therefore in total, 39 stories describing children's behaviours in domestic fires were included in a synthesis of findings from 3 studies; Jones (2012, n=19), Dowling (2002, n=1) and Park (1995, n=19). Perhaps not surprisingly, since these stories were not collated for the purpose of identifying children's behaviour in domestic fires per se, the majority of the stories were very brief. In addition, basic demographic information was missing. For example; the sex of the child was not known for 10 stories, and the age of the child was unknown in 19 stories. None of the reports included the ethnicity of the child. Thirty eight of the 39 stories were from the US. The origin of the fire was only reported in 18 stories; in four of these a child unintentionally started the fire. Across the 39 stories we identified a number of actions by the children that were considered good practice to ensure the safety of the child and others, together with actions reported by the children that placed them at increased risk of harm from the fire (Table 1).

Table 1: Appropriate and inappropriate behaviours reported by children

\begin{tabular}{|l|l|l|}
\hline Category & Behaviour & $\begin{array}{l}\text { Number of children } \\
\text { reporting this action }\end{array}$ \\
\hline Appropriate behaviours & $\begin{array}{l}\text { Initiation of own } \\
\text { evacuation from the } \\
\text { building }\end{array}$ & 19 \\
\hline
\end{tabular}




\begin{tabular}{|l|l|l|}
\hline & $\begin{array}{l}\text { Advising or helping other } \\
\text { people to leave the } \\
\text { building }\end{array}$ & 11 \\
\hline & $\begin{array}{l}\text { Calling emergency } \\
\text { services for help }\end{array}$ & 9 \\
\hline & $\begin{array}{l}\text { Alerting a grown up to the } \\
\text { fire }\end{array}$ & 8 \\
\hline Inappropriate behaviours & $\begin{array}{l}\text { Going to a pre-arranged } \\
\text { safe place* }\end{array}$ & 7 \\
& $\begin{array}{l}\text { Entering the room of } \\
\text { origin of the fire }\end{array}$ & 5 \\
\hline & $\begin{array}{l}\text { Returning into a building } \\
\text { where there was known to } \\
\text { be a fire after evacuation }\end{array}$ & 4 \\
\hline & $\begin{array}{l}\text { Attempting to put the fire } \\
\text { out }\end{array}$ & 3 \\
\hline
\end{tabular}

* these were children who had received the 'Learn not to burn' programme in the US, that included this recommendation

The evidence available provided no detail to enable the research team to understand the decision making of the children experiencing these fire situations. We were unable to determine why children undertook a particular sequence of actions, why they undertook those actions and whether they were making choices along the way and what was informing those decisions. 


\subsection{Conclusions}

\subsection{Summary of findings.}

Despite an extensive search we were unable to find any qualitative studies that had been specifically designed to facilitate understanding of children's behaviour and decision making in accidental dwelling fires. We did however identify 39 reports that very briefly mentioned children's behaviour in such fires from studies designed to either explore psychological consequences of fire exposure, or the effectiveness of fire safety education programmes, that yielded indicators to both positive (increased safety) and negative (increased risk) behaviours.

\subsection{Strengths and weaknesses of our study}

To our knowledge this is the first systematic literature review of qualitative research on this topic. Strengths of our study include the sensitive and systematic search strategy that was applied to 10 electronic databases of published research, and the significant grey literature searching we undertook to identify evidence not published in scientific journals included in the databases searched. We actively sought to make contact with all authors of included studies, and two (Jones (2012) and Dowling (2002)) were able to provide additional information. The data available for consideration in the synthesis was considerably increased by the provision of 19 transcripts meeting our inclusion criteria that were provided by Jones, despite these being collected more than 15 years previously. Limitations of our study include the fact that many of the included studies contained stories that were very brief and provided little detail of children's behaviour or decision-making. We acknowledge the risk that we may have missed qualitative literature meeting our inclusion criteria due to the fact that qualitative methods are often not coded in electronic databases. It 
was for this reason that we chose not to include methodological terms in our search strategy. It is possible that other studies that would have been suitable for inclusion were reported in specialist journals not included in the databases we searched. We identified four authors who had reported outcomes of interest for this review, even though these were not the primary outcome of interest to the authors themselves. We recognise therefore that we may have missed further studies where secondary outcomes were relevant to our research question.

\subsection{Comparison with existing literature.}

The evidence we have identified has originated from only three sources and there is a paucity of detailed, useful information in the stories. Most of the information is 1520 years old, and the lived experience of children in the UK today is very different to that of $15-20$ years ago. The evidence is almost entirely from the United States. We know that many of the fires described by the children may have little relevance to domestic fires in the UK where we are attempting to apply this evidence. For example, some of the fires were in trailer homes, many others were in timber framed houses, whilst the majority of children in the UK live in homes of brick or concrete construction. The ability to generalise the findings from this review is therefore limited and should be undertaken with caution. The literature describes people living in socio-demographic disadvantage as being at increased risk of experiencing an accidental dwelling fire (Mulvaney 2009, Marshall 1998, Warda 1999). The data identified through this review almost entirely failed to report information relating to socio-demographic variables and therefore interpretation on this important issue of inequality in risk was not possible. 
Authors of research on adult behaviours in fire have explored both pre-evacuation behaviour (Thompson 2014, Wales 2015), and how their perceptions of risk from the fire changed during their experience of the fire at home (Kinateder 2015, Clark 2015b, Wales 2015). This rich and insightful information is of direct relevance to understanding the consequent actions of the victims. The work of Thompson (2014) and Wales (2015) with adults illustrates how people may attempt to tackle the fire, support the evacuation of others, or rescue possessions and pets. Wales (2015) reports that these actions may knowingly involve exposure of the adult to the effects of the fire, with the driver for these 'inappropriate' behaviours appearing to be the perception that the fire can be contained and that they have the ability to do so, or that people, pets and possessions can be retrieved safely. The public make judgements on the level of risk from a domestic fire, and how quickly that risk may change as the fire takes hold. Clearly at times they are able to make safe judgements regarding those risks, for example, by successfully rescuing occupants prior to the arrival of the FRS. On other occasions however that judgement is poor with potentially fatal results. Respondents in the research led by Wales (2015) and Thompson (2014) indicated that some were reluctant to call the fire service due to embarrassment at either having allowed the fire to start or embarrassment that they were unable to contain the fire without recourse to external help. Understanding the motivations for behaviour in fires is therefore crucial to determining public safety messages and how call handlers should advise those reporting a fire in their home.

This review was only able to identify a limited number of stories from children of their behaviours in domestic fires, but on occasion these too were in contravention of the advice from the FRS to 'Get out, stay out, and call 999'. Importantly, the children's 
stories did not provide enough information to be able to understand the rationale for behaviours such as re-entering the room of origin of a fire, or returning into to a building known to contain a fire or how children perceive the risks associated with domestic fires. Unfortunately, the growing and increasingly rich literature on adult behaviours in fires does not appear to be replicated for children. This latter issue is particularly important. We know from research on road safety that children's ability to accurately judge a range of risks associated with safely navigating traffic as a pedestrian changes with their age and stage of development. Children under about 10 years may not be able to appropriately judge the speed of oncoming traffic (Wann 2011), the time taken to cross the road (O'Neal 2012), or the ability to use sensory cues (such as hearing) to assess risk (Pfeffer 1996). Such evidence now underpins road safety training for children. The fire safety literature does not contain similar evidence relating to perception of fire risks, or how these change with age. This illustrates the need to clearly understand children's abilities and motivations as well as their behaviours in order to generate fire safety information for children and young people that is meaningful and consequently more likely to be remembered and acted upon in the event of a fire. Within the children's stories identified in this review we did find examples where children had remembered information from a fire safety education programme and followed it through (such as removing yourself to a safe place). This indicates a potential for the content of fire safety education programmes to be helpful in domestic fire situations but the current evidence base underpinning those programmes appears less than adequate.

4.4 Implications for research and practice. 
This review contributes to the literature by illustrating a gap in the evidence. We have shown that we have very little valid evidence of how and why children behave as they do in an accidental dwelling fire. It suggests that asking children to tell their story of being in a fire at home may yield information on both safety and risk behaviours of children. Such studies therefore have the potential to be a valuable tool in providing evidence to support the development of fire safety education programmes that promote safety behaviours and discourage risk behaviours. In addition, better knowledge of how children behave in unintentional domestic fires and the reasons why they make those decisions has the potential to support the training of fire personnel who search burning buildings for children who require rescue. The limited evidence identified, and the paucity of evidence from the UK, indicates the need for further research to establish a UK-relevant evidence base.

\section{Funding and timescales}

The project was funded through the 2014/15 QR funding round of the Faculty of

Health and Applied Sciences, University of the West of England, Bristol.

The project commenced on $1^{\text {st }}$ August 2014 and ran until $31^{\text {st }}$ July 2015.

\section{References}

Bird, D., Culley, L., Lakhanpaul, M. (2013) Why collaborate with children in health research: an analysis of the risks and benefits of collaboration with children. Archives of Disease in Childhood: Education and Practice Edition. 0; 17. Doi:

10.1136/archdischild-2012-303470 
Bowling, A. (2014) Section V: Qualitative and mixed methods research. In: Research methods in health: Investigating health and health services. $4^{\text {th }}$ Edition. Oxford University Press. London.

Braun, V. and Clarke, V. (2006) Using thematic analysis in psychology. Qualitative Research in Psychology, 3 (2). pp. 77-101. ISSN1478-0887.

Chief Medical Officer (2012) Our Children Deserve Better: Prevention Pays. Available from

https://www.gov.uk/government/uploads/system/uploads/attachment data/file/25523 7/2901304 CMO complete low res accessible.pdf . [Accessed 14 June 2016].

Children Act (1989) London. HMSO. Available from:

http://www.legislation.gov.uk/ukpga/1989/41/contents . [Accessed 14 June 2016].

Children Act (2004) London. HMSO. Available from:

http://www.legislation.gov.uk/ukpga/2004/31/contents . [Accessed 14 June 2016].

Clark, A., Smith, J. and Conroy, C. (2015a) Domestic fire risk: a narrative review of social science literature and implications for further research. Journal of Risk Research. 18 (9), pp. 1113-1129.

Clark, A. and Smith, J. (2015b) Experiencing a domestic fire: an overview of key findings from a post incident research programme. Safer Communities. 14 (2), pp. 95-103.

Corbin, J., and Strauss A (2015) Basics of qualitative research: Techniques and procedures for developing Grounded Theory. Fourth edition SAGE Publication, London.

Department for Communities and Local Government. (2014a) English Housing Survey: Fire and Fire Safety, 2012-13. Available from:

https://www.gov.uk/government/uploads/system/uploads/attachment data/file/33575 7/EHS Fire and Fire Safety 2012-13.pdf . [Accessed 12 March 2016].

Department for Communities and Local Government. (2014b) Breathing apparatus: Operational Guidance. Available from:

https://www.gov.uk/government/uploads/system/uploads/attachment data/file/27115 7/131230-Operational Guidance Breathing Apparatus Web.pdf . [Accessed 12 March 2016].

Department for Communities and Local Government. (2015) Fire Statistics: Great Britain April 2013 to March 2014. Fire and Rescue Statistical Release. London. Available from https://www.gov.uk/government/uploads/system/uploads/attachment data/file/45665 2/Fire Statistics Great Britain 2013-14 PDF Version .pdf . [Accessed 12 March 2016]. 
Diekman, S., Ballesteros, M. and Ahern, M. (2012) Home fires in America: progress and opportunities. American Journal of Lifestyle Medicine. 6 (2), pp. 141-151.

Dowling, D. (2002) Child behaviour in fire. Fire Safety, Technology and Management. Spring 2002, pp. 13-17.

Greenberg, H.S. (1994) Responses of children and adolescents to a fire in their homes. Child and Adolescent Social Work Journal. 11 (6), pp. 475-492.

HM Government. (2015) Chapter 5: Child Death Reviews. In: Working together to safeguard children. Available from:

http://www.workingtogetheronline.co.uk/chapters/chapter five.html . [Accessed 12 March 2016].

Holborn, P., Nolan, P. and Golt, J. (2003) An analysis of fatal unintentional dwelling fires investigated by London Fire Brigade between 1996 and 2000. Fire Safety Journal. 38 (1), pp. 1-42.

Hussain, A. Dunn, K. (2014) Burn related mortality in Greater Manchester: 11 year review of regional Coronial department data. Burns. 41(2), pp. 225-234.

INVOLVE (2012) Briefing notes for researchers: public involvement in NHS, public health and social care research. Available from http://www.invo.org.uk/wpcontent/uploads/2014/11/9938 INVOLVE Briefing Notes WEB.pdf . [Accessed 14 June 2016].

Jones, R.T., Ollendick, T.H., Mathai, C.M., Allen, K. R., Hadder, J.M., Chapman, S. and Woods, B. (2012) "When I came home...Everything was gone." The impact of residential fires on children. Fire Technology. 48, pp. 927-943.

Jones, R.T. and Ollendick, T.H. (2002) Residential fires. In Helping Children Cope with Disasters and Terrorism. Eds: La Greca, A.M., Silverman, W. K., Vernberg, E.M. and Roberts, M.R. Washington: American Psychological Association.

Kinateder, M., Kugligowski, E., Reneke, P. and Peacock, R. (2015) Risk perception in fire evacuation behaviour revisited: definitions, related concepts and empirical evidence. Fire Science Reviews. 4 (1), DOI 10.1186/s40038-014-0005-z.

Kobes, M., Helsloot, I., de Vries, B. and Post, J. (2010) Building safety and human behaviour in fire: a literature review. Fire Safety Journal. 45, pp. 1-11.

Marshall, S., Runyan, C., Bangdiwala, S., Linzer, M., Sacks, J. and Butts, J. (1998) Fatal residential fires: who dies and who survives? Journal of the American Medical Association. 279 (20), pp. 1633-1637.

McDonagh, J., Bateman, B. (2012) 'Nothing about us without us': considerations for research involving young people. Archives of Disease in Childhood Education and Practice Edition. 97: 55-60. Doi: 10.1136/adc.2010.197947 
Mulvaney, C., Kendrick, D., Towner, E., Brussoni, M., Hayes, M., Powell, J., Robertson, S., Ward, H. (2009) Fatal and non-fatal fire injuries in England 19952004: time trends and inequalities by age, sex and area deprivation. Journal of Public Health. 31 (1), pp.154-161.

O'Neal, E., Plumert, J. and Schwebel, D. (2012). How well do children estimate the time it takes to cross a road? A risk factor for pedestrian injury. Injury Prevention. 18: A103-104. DOI: 10.1136/injuryprev-2012-040590d.24

Park, M. (1995) Fire safety education: making a difference. Moreton-in-Marsh: Fire Service College. (Brigade Command Course, 1995 no.2).

Petticrew, M. and Roberts, H. (2006) Chapter 6: Synthesizing the evidence. In: Systematic reviews in the social sciences. London: Blackwell Publishing, pp. 164190.

Pfeffer, K. and Barnecutt, P. (1996). Children's auditory perception of movement of traffic sounds. Child: Care, Health and Development. 22 (2): 129-137.

DOI:10.1111/j.1365-2214.1996.tb00780.x

Pope, C., Mays, N. and Popay, J. (2007) Chapter 2: Stages in reviewing evidence systematically. In: Synthesizing qualitative and quantitative health evidence: a guide to methods. London: McGraw Hill, pp. 19-44.

Runyon, C., Bangdiwala, S., Linzer, M., Sacks, J. and Butts, J. (1992) Risk factors for fatal residential fires. New England Journal of Medicine. 327 (12), pp. 859-863.

Shai D, Lupinacci P. (2003) Fire fatalities among children: an analysis across Philadelphia's census tracts. Public Health Reports. 15, pp. 115-126

Thompson, O. and Wales, D. (2014) A qualitative study of experiences, actions and motivations during accidental dwelling fires. Fire and Materials. DOI:

10.1002/fam.2248

UN General Assembly (1989). Convention on the Rights of the Child. Article 1.

Available from http://www.hakani.org/en/convention/Convention Rights Child.pdf. [Accessed 8 June 2016].

United Nations (1989). UN Convention on the Rights of the Child. Available from http://www.ohchr.org/en/professionalinterest/pages/crc.aspx . [Accessed 14 June 2016].

Wales, D., Thompson, O., Hulse, L. and Galea, E. (2015) From Data to Difference considering the application of a large-scale database of human behaviour in accidental dwelling fires. Presented at Human Behaviour in Fire 2015 (6 ${ }^{\text {th }}$ International Symposium). Cambridge. Copyright Interscience Communications Ltd. 
Wann, J., Poulter, D. and Purcell, C. (2011). Reduced sensitivity to visual looming inflates the risk posed by speeding vehicles when children try to cross the road. Psychological Science. 22 (4); 429-434. DOI: 10.1177/0956797611400917

Warda, L., Tenenbein, M., and Moffatt, M. (1999) House fire injury prevention update. Part 1. A review of risk factors for fatal and non-fatal house fire injury. Injury Prevention. 5 (2), pp. 145-150.

Xiong, L., Bruck, D. and Ball, M. (2015) Comparative investigation of 'survival' and fatality factors in accidental residential fires. Fire Safety Journal. 73, pp. 37-47.

Zhao, C., Lo, S., Liu, M. and Zhang, S. (2009) A post fire survey on the preevacuation human behaviour. Fire Technology. 45, pp. 71-95. 